\title{
Retrospective survey on efficacy of cefixime-ofloxacin 400 milligram sustained release fixed-dose combination tablet for enteric fever in community settings of India
}

\author{
Saiprasad Patil*, Krishnaprasad Korukonda, Amit Bhargava
}

\author{
Medical Services, Glenmark \\ Pharmaceuticals Ltd, India \\ Received: 22 October 2015 \\ Accepted: 06 November 2015 \\ *Correspondence to: \\ Dr. Saiprasad Patil, \\ Email: saipras300@gmail.com \\ Copyright: (C) the author(s), \\ publisher and licensee Medip \\ Academy. This is an open- \\ access article distributed under \\ the terms of the Creative \\ Commons Attribution Non- \\ Commercial License, which \\ permits unrestricted non- \\ commercial use, distribution, \\ and reproduction in any \\ medium, provided the original \\ work is properly cited.
}

\begin{abstract}
Background: The World Health Organization (WHO) estimate for annual global incidence of typhoid fever, about 21 million cases, is probably an underestimate because of poor diagnostics. Multi-drug resistant (MDR) isolates and nalidixic resistant isolates have limited the choice of oral drugs available for the treatment of typhoid fever. Recently the Indian regulatory authority approved an oral fixed dose combination (FDC) of cefixime and ofloxacin for the treatment of typhoid fever.

Methods: Retrospective survey was planned to observe the efficacy of cefixime-ofloxacin $400 \mathrm{mg}$ sustained release (SR) FDC tablet for enteric fever in community settings of India. Family physicians involved in the management of enteric fever cases were selected across 4 zones (East, South, West, and North) each by convenient sampling to have uniform representation of population across the country. Each physician was given survey questionnaire booklet containing survey forms.

Results: Total 78 family physicians participated in the survey with 881 completed questionnaire forms. Hypertension, diabetes were present in $83 \%$ $(\mathrm{N}=244)$ patients with comorbid conditions. One hundred and fifty four $(17.4 \%)$ cases revealed history of relapse or recurrence. Fever clearance rate of $97 \%$ was observed in overall evaluable population. Sub analysis in high risk cases (relapse/recurrence) showed equally good response to the combination as cases without defervescence on day 3 and day 7 were only $21.4 \%$ and $1.3 \%$ respectively.

Conclusions: Based on the present study we believe that cefixime-ofloxacin 400mg SR FDC to be an appropriate choice in the management of resistant enteric fever cases, especially in presence of comorbid conditions like hypertension or diabetes which adds to excess pill burden.
\end{abstract}

Keywords: Sustained release (SR), MDR isolates, Fixed-dose combination (FDC), retrospective survey

\section{INTRODUCTION}

Water and food borne infections like enteric fever continue to be a major cause of ill health and death especially in the developing world with an estimated 26.9 million episodes in 2010. ${ }^{1}$ The infection manifests as fever with non-specific signs and symptoms like loss of appetite, fatigue, splenomegaly and hepatomegaly. The annual global burden of typhoid fever as per World Health Organization (WHO) estimate, about 21 million cases, is probably an underestimate because of lack of good diagnostic support. ${ }^{2}$ Multiple options for diagnosing enteric fever including serological tests; bacterial culture; antigen detection; and nuclear amplification are available but none is entirely satisfactory. ${ }^{3}$ In clinical practice diagnosis is generally aided by culture of the organism from blood and/or bone marrow in the first and second weeks of illness and by serological tests like Widal test in the second week of illness, but access to such laboratories are uncommon in resource-poor regions. ${ }^{4,5}$ Untreated the mortality rate is as high as $30 \%$ which can be reduced to as low as $0.5 \%$ with appropriate therapy. ${ }^{6}$

The development of antimicrobial resistance among this organism has emerged as a major community healthcare. MDR isolates (resistant to chloramphenicol, ampicillin and trimethoprime-sufamethoxazole) and nalidixic resistant isolates (marker of fluoroquinolones resistance) 
have limited the choice of oral drugs available for the treatment of typhoid fever. Though the level of MDR isolates has reduced with lower usage of the first line drugs, still the challenge of treatment with an oral drugs remains and the consequence of concomitant usage of all classes of drugs remains unknown. Recently the Drugs Controller General (India) approved an oral FDC of cefixime and ofloxacin for the treatment of typhoid fever. However, there is sparse data available on this combination against enteric fever cases.

We have conducted a retrospective survey based on a simple questionnaire to assess the clinical response in the suspected enteric fever cases to cefixime-ofloxacin SR combination in Indian community setting.

\section{METHODS}

Retrospective survey was carried out to observe the efficacy of cefixime-ofloxacin $400 \mathrm{mg}$ SR FDC tablet for enteric fever in community settings of India. Survey period was from October 2014 - March 2015. Family physicians involved in the management of enteric fever cases with cefixime based combinations were identified through "SCRIP intelligence" database. Among these 25 doctors who were keeping the patients clinical record were selected across 4 zones (East, South, West, and North) each by convenient sampling to have uniform representation of population across country. Each physician was given survey questionnaire booklet containing survey forms. Survey questionnaires included information as - demography, relevant medical history, laboratory investigations (CBC, Widal), and fever clearance in terms of control of fever (Axillary temperature $<98.6^{\circ} \mathrm{F}$ ) on day 3 and day 7 .

\section{RESULTS}

Total 78 family physicians participated in the survey out of 100 selected doctors, from whom a total of 989 survey forms were collected at the end of 6 months period (April 2015). Eight hundred and eighty one completed survey questionnaire forms were included for further evaluation (Table 1). The baseline demographic parameters from the evaluable survey forms representing gender, age, medical history amongst the patients are shown in (Table 1).

Hypertension, diabetes were present in $83 \%(\mathrm{~N}=244)$ patients with comorbid conditions. Drug history for comorbid conditions was not captured. History of enteric fever in past one year was captured in 154 (17.4\%) forms as relapse or recurrence, which were considered as high risk cases. Bodyache $(\mathrm{N}=513)$ was the most common symptom followed by headache $(\mathrm{N}=356)$, loss of appetite $(\mathrm{N}=340)$, diarrhoea $(\mathrm{N}=158)$ and constipation $(\mathrm{N}=156)$ (Figure 1).

No rising titre was recorded in Widal test, but ' $\mathrm{O}$ ' titre more than 100 was captured in 238 forms, demonstrating microbiologically confirmed enteric fever in $27 \%$ cases.
Past history of antibiotic exposure within 3 months was captured in $175(20 \%)$ cases. Average white cell count (in $\times 1000$ per microliter) was 6.7 (range 1-24). Cefiximeofloxacin $400 \mathrm{mg}$ SR FDC tablet was prescribed once daily in 580 patients out of all cefixime based combinations with the duration ranging from 5 to 14 days depending upon physician's clinical judgement.

Table 1: Baseline demographic parameters of the evaluable survey forms $(\mathrm{N}=881)$.

\begin{tabular}{|lll|}
\hline $\begin{array}{l}\text { Survey details } \\
\text { Average age of } \\
\text { population }\end{array}$ & $\begin{array}{l}\text { Number of } \\
\text { patients } \\
87.8(14 \text { yrs. }-\end{array}$ & $\begin{array}{l}\text { Percentage of } \\
\text { patients }\end{array}$ \\
\hline $\begin{array}{l}\text { Gender } \\
\text { Males }\end{array}$ & 575 & $65.26 \%$ \\
\hline Females & 306 & $34.73 \% \%$ \\
\hline $\begin{array}{l}\text { History of } \\
\text { antibiotics in } \\
\text { past 3 months }\end{array}$ & 175 & $19.86 \%$ \\
\hline Comorbid conditions $(\mathrm{N}=244)$ & \\
\hline Diabetes & 97 & $39.75 \%$ \\
\hline Hypertension & 106 & $43.44 \%$ \\
\hline Others & 41 & $16.8 \%$ \\
\hline
\end{tabular}

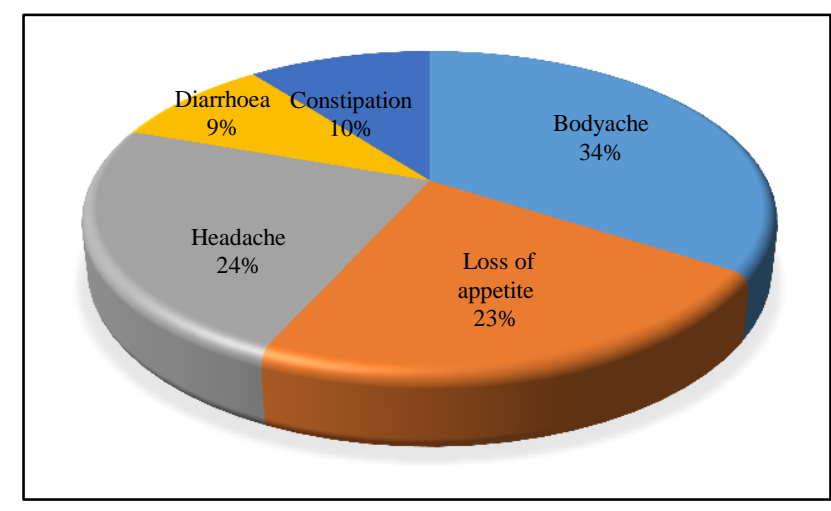

Figure 1: Symptomatic distribution of survey population $(\mathrm{N}=881)$.

Data for fever response to the combination showed fever clearance in $565(97 \%)$ cases by $7^{\text {th }}$ day. Sub analysis in high risk cases (relapse/recurrence) showed equally good response to the combination as cases without defervescence on day 3 and day 7 were $21.4 \%$ and $1.3 \%$ respectively (Figure 2).

\section{DISCUSSION}

Febrile illness is one of the most common presentations of enteric fever encountered in general practice. The emergence of MDR S. Typhi has rendered chloramphenicol, ampicillin, cotrimoxazole, and older fluoroquinolones useless as therapy for typhoid. ${ }^{7}$ In the current scenario of high rate of fluoroquinolones resistance, third generation cephalosporins have become the drug of choice, and azithromycin is also increasingly 
being used in the treatment of typhoid fever ${ }^{2}$. Though cephalosporin resistance have been slow to develop, nevertheless, strains producing extended spectrum beta lactamases have been reported. ${ }^{2}$

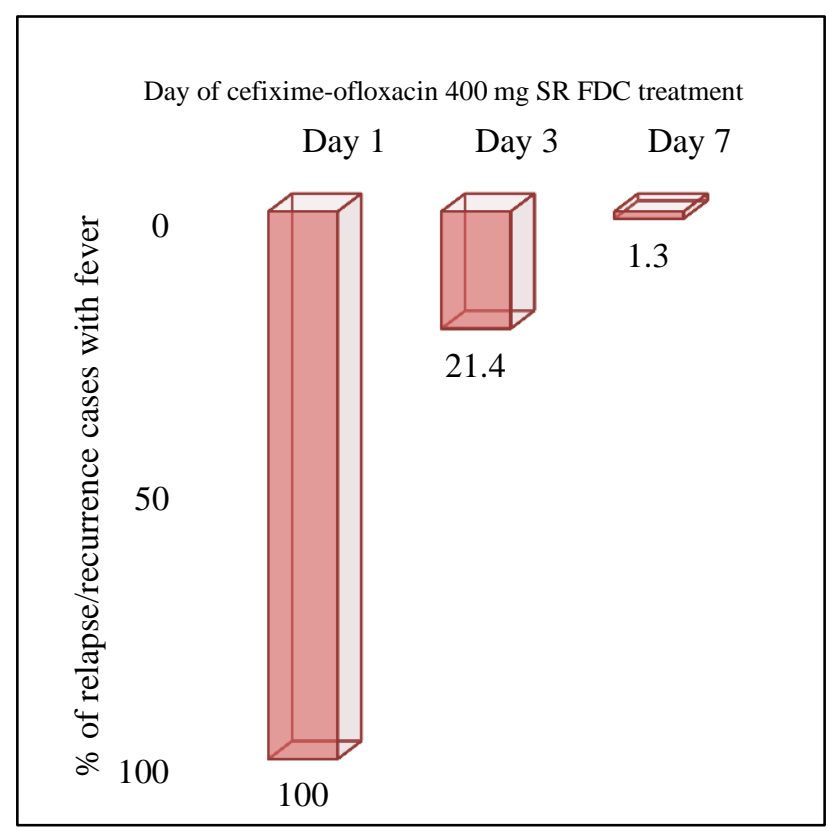

Figure 2: High risk cases (relapse/recurrence) enteric fever cases without defervescence post cefiximeofloxacin $400 \mathrm{mg}$ SR FDC treatment $(\mathrm{N}=154)$.

The combination of Cefixime with Ofloxacin in the management of typhoid fever was approved by the regulatory authorities in India. ${ }^{8}$ Moreover, WHO has recommended use of cefixime, fluoroquinolones in the management of MDR typhoid fever cases.

Cefixime-ofloxacin 400mg as a SR tablet is marketed by Glenmark and indicated in typhoid fever once in a day. Sustained release dosage forms releases a drug at a predetermined rate hence able to maintain a constant drug level for a specific period of time with minimum side effects. Hydrophilic polymer upon contact with water hydrates to form a viscous gel layer around the tablet surface, and controls drug release in a sustained manner by diffusion through a gel layer and the erosion of the gel. Additionally sustained release dosage forms helps in improving patient compliance by reducing frequency of dose. ${ }^{9}$ This in turn can result in completion of treatment which is important in complete cure in enteric fever cases and avoidance of relapse or recurrence. In our retrospective survey the overall fever clearance rate of $97 \%$ by day 7 particularly in relapse or recurrence cases, suggests that cefixime-ofloxacin $400 \mathrm{mg}$ SR tablet as a prudent choice for the treatment of enteric fever.

Non-comparative evaluation study by Naik et al. reported rapid clinical cure of enteric fever with FDC of cefixime and ofloxacin as assessed by mean fever defervescence time of 4.9 days. $^{10}$ Similarly, Faruqui AA et al. reported significant improvement in fever reduction, respiratory rate normalization from baseline to day 3 and day 7 of treatment $(\mathrm{N}=30)$ respectively with cefixime and ofloxacin FDC. ${ }^{11}$

Drug adherence among elderly is an important health care concern with compliance rates varying from $0 \%$ to $59 \%$. Pill burden plays a vital role particularly in patients with comorbid conditions like uncontrolled diabetes mellitus $(\mathrm{p}<0.01)$ and uncontrolled hypertension $(\mathrm{p}<0.05)$ as confirmed by Kumar et al. ${ }^{12}$

In our retrospective survey hypertension, diabetes were present in $83 \% \quad(\mathrm{~N}=244)$ of patients with comorbid conditions, which adds to excess pill burden. FDC dosage forms reduces the risk of drug non-compliance and should specifically opt in patients with underlying comorbid conditions like diabetes, hypertension for better clinical outcomes. ${ }^{13}$

\section{CONCLUSION}

Based on the present study we believe that cefiximeofloxacin 400mg SR FDC to be an optimal choice in the treatment of MDR enteric fever cases, especially in presence of comorbid conditions like hypertension or diabetes which adds to excess pill burden. Well designed, randomized, comparative, prospective study evaluating the efficacy and safety of cefixime and ofloxacin 400mg SR FDC in resistant enteric fever cases with subgroup of relapse or recurrent cases and underlying comorbid conditions will further confirm the findings from our survey.

\section{ACKNOWLEDGEMENTS}

The authors would like to thank the esteemed doctors for their kind participation in this survey. These doctors include- Dr. Manohar Lal Harzani, Dr. Kaushik Savaliya, Dr. L B Morya, Dr. C K Narware, Dr. M I Haque, Dr. Kamlesh Thakur, Dr. P C Sodhiya, Dr. R C Verma, Dr. K K Biswas, Dr. S Panjabi, Dr. Sanjay Kumar Gandhi, Dr. Jyoti Upadhyay, Dr. Kronal Chaudhary, Dr. Sarfaraz Ansari, Dr. Suresh Patel, Dr. Prashant R Salve, Dr. Shrikant B Dighe, Dr. Pravin Shankar Pingale, Dr. Vijay Dhondage, Dr. Praveen Suryawanshi, Dr. Subodh Kumar, Dr. Satish Arora, Dr. Islam Khan, Dr. B K Gupta, Dr. Ravindra Singh, Dr. R.S.Dodhiyal, Dr. V.K.Maghs, Dr. Radheyshyam Garg, Dr. Kirti Patel, Dr. R U Motwani, Dr. Prasad Kr Gupta, Dr. Nupur Gupta, Dr. Manish Raninga, Dr. Girish Patel, Dr. Pinkesh Jikadra, Dr. Ashok Patel, Dr. Ajit K Bora, Dr. P. C. Malan, Dr. H.L. Parihar, Dr. Manoj, Dr. Mahavir, Dr. Rajdeo Singh Yadav, Dr. R.D. Mishra, Dr. Sanjay Garg, Dr. Yogendra Kumar Mishra, Dr. Pankaj K. Updhyay, Dr. Kiran Parmale, Dr. Prashant J. Tekade, Dr. J.K. Dolak, Dr. Sayyed mohatsim, Dr. Bharat Paliwal, Dr. G. D. Gandhi, Dr. Chandrakant Chate, Dr. Bhojane Shivaji, Dr. Vivek Kashyap, Dr. Sadanand R. Gandhe, Dr. K.C. Das, Late Dr. Debesh Sahu, Dr. Manoj Senapati, Dr. P.K. Jena, Dr. Shanta Neevedita, Dr. Sarthak Sanket Biswal, Dr. S.K. 
Rao, Dr. Dilip Bislal, Dr. Santosh K. Tulo, Dr. B.P. Choudhry, Dr. Prasanta kumar Pradhan, Dr. Satyasai Nayak, Dr. Muktiranjan Panigrahi, Dr. Tanveer Hamid, Dr. Abhishek Kumar, Dr. Anand Kumar, Dr. M.K. Lakhotia, Dr. Manoj Kumar Ram, Dr. Jagdish Tuteja, Dr. J. N. Trivedi, Dr. Rakesh Kumar, Dr. Sanjay Jain.

Funding: Study support in the form of survey booklets. Conflict of interest: None declared

Ethical approval: Not required

\section{REFERENCES}

1. Buckle GC, Walker CLF, Black RE. Typhoid fever and paratyphoid fever: Systematic review to estimate global morbidity and mortality for 2010. J Glob Health. 2012;2(1):010401.

2. Wain J, Hendriksen RS, Mikoleit ML, Keddy KH, Ochiai RL. Typhoid fever. Lancet. 2014;385(9973):1136-45.

3. Wain J, Hosoglu S. The laboratory diagnosis of enteric fever. J Infect Dev Ctries. 2008;2(06):421-5.

4. D S. The diagnosis, treatment and prevention of typhoid fever, 2013. (WHO/V\&B/03.07)

5. http://whqlibdoc.who.int/hq/2003/WHO_V\&B_03.0 7.pdf.

6. Ochiai RL, Acosta CJ, Danovaro-Holliday MC, Baiqing D, Bhattacharya SK, Agtini MD, et al. A study of typhoid fever in five Asian countries: disease burden and implications for controls. Bull World Health Organ. 2008;86(4):260-8.

7. Harish BN, Menezes GA. Antimicrobial resistance in typhoidal salmonellae. Indian $\mathrm{J}$ Med Microbiol. 2011;29(3):223-9.
8. Pandit A, Arjyal A, Day JN, Paudyal B, Dangol S, Zimmerman MD, et al. An open randomized comparison of gatifloxacin versus cefixime for the treatment of uncomplicated enteric fever. PLoS One. 2007;2(6):e542.

9. Fixed dose combinations approved by DCG (I) since 1961 till December, 2013. http://cdsco.nic.in/forms/list.aspx?lid=1820\&Id=11.

10. Jaimini M. Sustained release matrix type drug delivery system: A review. Journal of Drug Delivery \& Therapeutics, 2012.

11. Naik M, Braganza L, Nair S. Open non-comparative evaluation of fixed dose combination of cefixime and ofloxacin in the treatment of uncomplicated typhoid fever. Ind Med Gaz. 2010;415-20.

12. Faruqui AA. Evaluation of efficacy and safety of fixed dose combination of cefixime and ofloxacin (CO2 Tablet) in the management of typhoid fever. Indian J Basic Appl Med Res. 2012;1(4):296-303.

13. Kumar A, Kumar J, Iyer SB, Kumar PK. Impact of pill burden and socio-economic status of patients on adherence to pharmacologic therapy in elderly. West Lond Med J. 2014;6(1):23-8.

14. Bangalore S, Kamalakkannan G, Parkar S, Messerli FH. Fixed-dose combinations improve medication compliance: a meta-analysis. Am J Med. 2007;120(8):713-9.

Cite this article as: Patil $\mathrm{S}$, Korukonda $\mathrm{K}$, Bhargava A. Retrospective survey on efficacy of cefiximeofloxacin 400 milligram sustained release fixed-dose combination tablet for enteric fever in community settings of India. Int J Basic Clin Pharmacol 2015;4:1043-6. 